Revue

Revue de l'histoire des religions

de Ihistoire

des religions

$3 \mid 2016$

Varia

Véronique FERRER, Exercices de l'âme fidèle. La littérature de piété en prose dans le milieu réformé francophone (1524-1685)

Genève, Droz, (« Travaux d'Humanisme et de Renaissance », 524), 2014

Audrey Duru

\title{
OpenEdition
}

Journals

Édition électronique

URL : http://journals.openedition.org/rhr/8613

DOI : $10.4000 /$ rhr.8613

ISSN : 2105-2573

Éditeur

Armand Colin

Édition imprimée

Date de publication : 1 septembre 2016

Pagination : 452-455

ISBN : 978-2-200-93061-5

ISSN : 0035-1423

Référence électronique

Audrey Duru, "Véronique fERRER, Exercices de l'âme fidèle. La littérature de piété en prose dans le milieu réformé francophone (1524-1685) », Revue de l'histoire des religions [En ligne], 3 | 2016, mis en ligne le 06 octobre 2016, consulté le 23 septembre 2020. URL : http://journals.openedition.org/rhr/8613 ; DOI : https://doi.org/10.4000/rhr.8613

Ce document a été généré automatiquement le 23 septembre 2020.

Tous droits réservés 


\section{Véronique FERRER, Exercices de l'âme fidèle. La littérature de piété en prose dans le milieu réformé francophone (1524-1685)}

Genève, Droz, (« Travaux d'Humanisme et de Renaissance », 524), 2014

\section{Audrey Duru}

\section{RÉFÉRENCE}

Véronique FERRER, Exercices de l'âme fidèle. La littérature de piété en prose dans le milieu réformé francophone (1524-1685), Genève, Droz, ( « Travaux d'Humanisme et de Renaissance », 524), 2014, 24,5 cm, 376 p., $65 €$, ISBN 978-2-600-01746-6.

1 L'ouvrage de Véronique Ferrer partage avec son objet le souci de transmettre un savoir tout en s'adressant aussi à la sensibilité du lecteur. L'instrument permet de s'orienter dans un massif de textes de piété réformée écrits en français, sur deux siècles, de la diffusion du luthéranisme en milieu francophone à la révocation de l'édit de Nantes. Écrite dans une langue élégante, l'étude est d'une lecture fluide et agréable, qui la rend accessible aux spécialistes des divers domaines que son objet intéresse : historiens du christianisme, en particulier de la naissance et du développement de la Réforme en Europe, spécialistes de littérature française humaniste, historiens du livre. Les érudits chevronnés tout comme les étudiants novices trouveront matière à actualiser, compléter et préciser leurs connaissances. Neuf chapitres de trois cents pages sont complétés par la table des matières de deux amples traités de préparation à la mort (Goulart, 1606; Drelincourt, 1651), une bibliographie générale, une utile bibliographie chronologique des éditions originales identifiées et un index des principaux auteurs commentés. 
2 Sous l'angle documentaire, cette étude des livres de piété en prose, en français et en milieu réformé, pour les $\mathrm{xvI}^{\mathrm{e}}$ et $\mathrm{xvII}^{\mathrm{e}}$ siècles approximativement, établit des perspectives synthétiques inédites. Elle identifie au sein du livre religieux un ensemble d'ouvrages en langue vernaculaire défini par son ambition pratique séculière - livrer une interprétation surnaturelle des affects et christianiser les comportements - plutôt que par une ambition spéculative ou contemplative servant un projet ecclésial. Les choix qui régissent l'établissement du corpus tendent à concentrer l'étude sur une pratique d'écriture, de laquelle résulte un genre de texte instable: la méditation biblique, adaptée aux circonstances historiques communautaires et individuelles (chap.1-5). La paraphrase en prose des psaumes, à laquelle deux chapitres sont consacrés ( 3 et 4$)$, en serait l'accomplissement littéraire exemplaire. Différentes séries de livres en lisière du projet sont exclues: les ouvrages de piété en latin (parfois mentionnés lorsqu'ils sont ensuite traduits), les traductions, en général, à partir d'autres langues vernaculaires, les commentaires bibliques à dominante exégétique, les nombreux livres de piété en vers. De fait, il apparaît souvent dans les notes infrapaginales qu'aucun écrit religieux à cette date ne saurait être dépourvu de valeur pratique et de fonction pieuse, notamment si le public visé n'est pas celui des professionnels de la foi. Certains textes sont donc plus représentatifs que d'autres du "livre de piété réformé", en fonction de ce qui reste une étiquette commode par provision. Pour certaines périodes, il existe des instruments bibliographiques identifiant les livres étudiés, notamment pour les débuts de la Réforme jusqu'à l'installation des Églises réformées à la fin du Xvi e siècle (Chaix, Dufour, Moeckli, 1966 ; Higman, 1996 ; Gilmont, 2006). L'étude de V. Ferrer augmente nos connaissances d'une lecture synthétique de ces ouvrages, d'un cadrage générique et de précisions sur les relations intertextuelles qu'ils entretiennent entre eux. Au fil des deux siècles, nous voyons ainsi un corpus dévot rédigé le plus souvent par des pasteurs se constituer de manière cumulative. Le dépouillement mené par V.Ferrer est concomitant de la réémission sous forme numérique d'un grand nombre des textes étudiés. Son positivisme sans pesanteur érudite permet au lecteur de s'orienter parmi cette somme de textes récemment rendus plus accessibles.

3 L'approche retenue est celle d'une « histoire littéraire du livre de piété en prose dans le milieu réformé européen francophone ». Un essai de périodisation met en évidence des dominantes éditoriales au cours des deux siècles (p.16-19) : les années 1524-1566 sont celles de la naissance d'une pastorale réformée par le livre de piété et de la création d'un public; les années 1574-1630 voient l'affirmation du livre de piété parmi d'autres livres de la librairie protestante à dominante plus doctrinale et didactique ; entre 1630 et 1685 , la pastorale par le livre double, voire complète la prédication homilétique et le rite liturgique. Certains aspects du programme annoncé par l'auteur laissent attendre des développements sur l'histoire de la fabrication du livre, sa diffusion et sa réception. Si le travail de composition et de mise en recueil est pris en considération, l'approche matérielle reste limitée: le travail dans l'atelier de l'imprimeur, la médiation des éditeurs, la notion de marché éditorial, le réseau de diffusion en Europe et au-delà, la chronologie des rééditions et de la rémanence des livres dans les lectures du public, la circulation en milieu catholique, ainsi que les occurrences repérables de la réception effective ne sont pas traités de façon systématique. Sur ces points, le chapitre 8 offre des aperçus suggestifs à partir de la figure du pasteur auteur. Sur la question de la réception, la construction rhétorique de la figure du lecteur ainsi que l'étude des destinataires des livres (chap. 9) suscitent la curiosité sur le public d'élite identifié et la 
lecture effective des volumes. Ils pourraient être cernés en première approximation à partir des inventaires après décès, ainsi que par d'autres traces de réception sous la forme d'imitations ou de textes d'éloge (poèmes brefs encomiastiques, par exemple).

4 L'approche d'histoire littéraire mise en œuvre s'efforce en fait de situer dans un contexte historique (politique, religieux, social, littéraire) non pas le livre, mais des pratiques d'écriture. Les choix rhétoriques et poétiques font l'objet d'un examen destiné à mettre à l'épreuve la validité du concept d'identité confessionnelle en matière littéraire (p. 25). Ce sont donc les formes de la prose méditative en milieu réformé qui sont scrutées avec une attention inédite. Le paradoxe apparent de la piété calviniste est rappelé dès l'introduction: à quoi bon des exercices dévots si aucun acte de vertu naturelle ne saurait permettre le salut du fidèle ? La piété participe en fait elle-même de la grâce obtenue sans mérite, par miséricorde. La foi vécue est déchiffrée comme un signe de la justification et de l'élection individuelle, manifestant ainsi une communauté d'élus. Dans ce cadre anthropologique calviniste, l'ensemble des écrits de piété participe d'une lecture actualisante de la Bible, livrant une herméneutique tant du texte que du méditant, dans une "démarche exhortative» pastorale de portée individuelle et communautaire.

Cet essai de critique confessionnelle examine globalement la pratique de la « langue de Canaan » (chap. 7), «artefact stylistique servant d'identifiant confessionnel » (p. 245). $\mathrm{Au}$ long des manuels et des sommes livresques, on note que la lecture morale de l'histoire contemporaine se fait au filtre des épîtres de l'apôtre Paul : elles donnent aux persécutions la valeur de tribulations pédagogiques façonnant les vertus de patience et d'espérance, et de signes d'élection. Au croisement du genre antique et patristique de la consolation d'une part et des traités de préparation à la mort d'autre part apparaît l'ampleur d'une pastorale réformée de la compassion: voir notamment les écrits de L'Espine, Goulart, Taffin, Merlin, Du Moulin, Comble, Durant, Drelincourt dans le chapitre 2. Les morceaux de bravoure que sont les études réunies dans les chapitres 3 et 4 sur les méditations psalmiques en prose (publiées de 1583 à 1630) interrogent la littérarisation du discours religieux. Depuis la fin du siècle dernier, le lecteur redécouvre ces méditations sur les psaumes à travers leur réédition critique et seules manquent encore provisoirement celles de La Roche-Chandieu et de Pellisson. Le parcours des textes de La Roche-Chandieu, Bèze, Duplessis-Mornay, Sponde et Aubigné offre un panorama contrastif et nuancé de leurs pratiques d'écriture: choix des modèles rhétoriques, variété de l'expression pathétique, actes de langage religieux sont scrutés pour chaque texte. Les pages consacrées aux textes de Sponde (p.151-162) soulignent ainsi la singularité de sa "fureur méditative », de laquelle il résulte que le psaume " donne le branle à la parole méditative sans pour autant l'habiter ». Il apparaît que Sponde ne médite pas en pasteur, ce qu'il n'est pas, mais en homme de Lettres. Poéticien commentateur d'Homère, modifiant de la sorte «le contrat spirituel et pastoral du méditant, sans pour autant dénaturer sa foi », il fait de sa personnalité littéraire un signe d'élection.

6 L'entreprise éditoriale réformée des $\mathrm{XVI}^{\mathrm{e}}$ et XVII $\mathrm{Xì̀}^{\mathrm{e}}$ les parait compenser la récusation des médiations traditionnelles en donnant au fidèle le modèle d'une langue qui soit centrée autant sur Dieu que sur l'individu. Les analyses fouillées de V. Ferrer rendent justice à la dimension tant anthropologique que spirituelle de cet usage religieux des Lettres. 


\section{AUTEURS}

AUDREY DURU

Université de Picardie - Jules Verne, Amiens. 